TITLE:

\title{
Uptake and retention of radio- caesium in earthworms cultured in soil contaminated by the Fukushima nuclear power plant accident.
}

\section{$\operatorname{AUTHOR}(S):$}

Fujiwara, K; Takahashi, T; Nguyen, P; Kubota, Y; Gamou, S; Sakurai, S; Takahashi, S

\section{CITATION:}

Fujiwara, K ...[et al]. Uptake and retention of radio-caesium in earthworms cultured in soil contaminated by the Fukushima nuclear power plant accident.. Journal of environmental radioactivity 2015, 139: 135-139

\section{ISSUE DATE:}

2015-01

URL:

http://hdl.handle.net/2433/192993

\section{RIGHT:}

(C) 2014 Elsevier Ltd.; This is not the published version. Please cite only the published version.; この論文は出版社版でありません。引用の際に は出版社版をご確認ご利用ください。 


\section{Uptake and retention of radio-caesium in earthworms cultured in soil contaminated by the Fukushima nuclear power plant accident}

K. Fujiwara ${ }^{1}$, T. Takahashi ${ }^{1}$, P. Nguyen ${ }^{1}$, Y. Kubota ${ }^{2}$, S. Gamou ${ }^{3}$, S. Sakurai ${ }^{4}$, S. Takahashi ${ }^{1}$

1) Radiation Safety and Control Department of Research Reactor Institute, Kyoto University Kumatori-cho, Sennan-gun, Osaka 590-0494, Japan

2) National Institute of Radiological Sciences,

Anagawa, Inage-ku, Chiba-shi, Chiba 263-8555, Japan

3) Kyorin University,

Miyashita-cho, Hachioji-shi, TOKYO 192-8508 JAPAN

4) Osaka Prefecture University,

Gakuen-cho, Nakaku, Sakai, Osaka 599-8531, JAPAN

Corresponding Author:

Keiko Fujiwara

E-mail:

fujiwara@rri.kyoto-u.ac.jp

Tel.:

+81-72-451-2478 


\section{Abstract}

To understand the effects of radionuclides on non-human biota and the environment, it is essential to study the intake and metabolism of radio-isotopes in earthworms which are among the most important soil organisms, and Eisenia fetida, which were used in this study, are known to be sufficiently sensitive to chemicals and representative of common earthworms. In this study, we assessed the concentration ratios, uptake and retention, absorbed dose rate, and distribution of radio-caesium in earthworms. The concentration ratios of ${ }^{137} \mathrm{Cs}$ (i.e., the concentrations of radio-caesium in earthworms relative to those in dry soil) were higher early in the culturing period and decreased gradually over the experimental period. ${ }^{137}$ Cs taken up by E. fetida was cleared rapidly after the worms were cultured in radio-caesium-free soil, suggesting that the metabolism of radio-caesium in earthworms is very rapid. Autoradiography demonstrated that the concentration of radio-caesium within the digestive tract was as high as that in the soil, while radio-caesium in the body tissue was lower than radio-caesium in the soil and was almost uniformly distributed among earthworm tissues. The highest absorbed dose rate of total exposure to radio-caesium $\left({ }^{137} \mathrm{Cs}+{ }^{134} \mathrm{Cs}\right)$ was calculated to be $1.9 \times 10^{3}(\mu \mathrm{Gy} /$ day) in the earthworms.

\section{Highlights}

We assessed the concentration ratios of ${ }^{137} \mathrm{Cs}$ in earthworms/dry soil.

The distribution of radio-caesium was relatively uniform throughout the earthworm body without any distinguishable accumulation in specific organs or tissues.

We estimated the absorbed dose rate of radio-caesium for earthworms.

\section{Keywords}

Radio-cesium; Earthworm; Fukushima nuclear power plant accident; Soil

\section{Introduction}

There has been increasing concern about the effects of radiation and/or radionuclides on non-human biota. The International Commission on Radiological Protection (ICRP) has indicated the importance of this subject (ICRP, 2003, 2007), and other international authorities have also expressed interest in its study. To assess the effects of radiation on non-human biota and the overall environment, it is essential to estimate typical doses of radiation and to understand the metabolism of radionuclides. However, only limited data are available on the metabolism of radionuclides in non-human biota.

Earthworms are common soil organisms and play an important role in numerous soil processes 
(Lavelle et al., 1997). Earthworms are also recognized as ideal soil organisms for use in terrestrial ecotoxicological studies and have been used as indicator animals for contaminated land (Greig-Smith et al., 1992). The ICRP assigned the earthworm as a reference animal for assessing effects of radiation on the environment (ICRP Pub108, 2009).

Radio-cesium, mainly ${ }^{137} \mathrm{Cs}$ and ${ }^{134} \mathrm{Cs}$, emits gamma and beta radiation with a relatively long half-life; these radio-isotopes are produced by the nuclear industry. A large amount of radio-caesium was emitted to the environment by the Tokyo Electric Power Company's Fukushima Daiichi nuclear power plant accident. The United Nations Scientific Committee on Atomic Radiation recently described in a report to the UN General Assembly that there is a potential risk to organisms in the areas of highest exposure, but this risk is difficult to quantify with the available information (UNSCEAR, 2013).

In this paper, we describe the uptake and retention of radio-caesium in genetically well-defined earthworms. The soils used were collected near the accident site. The distribution of radio-caesium in the earthworms and surrounding soil were examined by autoradiography, and absorbed dose rates were estimated.

\section{Materials and Methods}

\subsection{Earthworms (Eisenia fetida)}

The earthworms used in this study, Eisenia fetida, are known to be sufficiently sensitive to chemicals and representative of common earthworms (Fritzpatrick et al., 1996). This species is commonly found in soil and compost, standing manure heaps, and sewage filter beds (Janssen et al., 1996). The earthworms were obtained from the laboratory of Prof. Gamou, Kyorin University, and has had their genetic background determined previously (Suzuki et al., 2008). This species are slightly different at the allied species level from those in Japan, but will give standard data to be able to use for actual situations. Worms were maintained in a commercial leaf mold for plant culture (peat moss, Keiyo Co., Ltd.) and given oatmeal powder and water once or twice a month. Adult earthworms ( $\mathrm{n}=$ 95) with an individual mass of 310-920 mg were selected and moved to a mixture of the commercial leaf-mold and rice-field or land soil containing radio-caesium. The worms were cultured in this medium for 1-36 days, and the worms were removed at scheduled time intervals for measurement or autoradiography. 


\subsection{Soil and ${ }^{137}$ Cs activity}

Organic surface soils at depths of $3-5 \mathrm{~cm}$ were collected with a hand scoop from the O layer, consisting of decomposed organic material, and the A layer, the mineral horizon containing substantial humus and dark color soil, in both a rice paddy field and in a land with weeds between the road and a cryptomeria forest in Fukushima Prefecture. The locations at which soils were collected are shown in Fig. 1. For experimental exposure of the earthworms, these radioactive soils were mixed with an equal mass of the commercial leaf mold described above. These two mixed soils are referred as soil A, using soil collected from the rice paddy field, and soil B, using soil collected from the land with weeds, hereafter. Bulk specific gravity, moisture content, and radioactive concentration of ${ }^{137} \mathrm{Cs}$ for soils $\mathrm{A}$ and $\mathrm{B}$ were 0.4 and $1.0 \mathrm{~g} / \mathrm{cm}^{3}, 68 \%$ and $73 \%$ (mass basis), and 49.1 and $162.4 \mathrm{~Bq} / \mathrm{g}$ dry mass, respectively. The Ministry of Agriculture, Forestry and Fisheries reported in Agriculture, Forestry and Fisheries Research Council that the concentration of ${ }^{137} \mathrm{Cs}$ for agricultural field soils in Fukushima Prefecture were from undetectable to $203,000 \quad \mathrm{~Bq} / \mathrm{kg}$ (203Bq/g) (http://www.s.affrc.go.jp/docs/map/240323.htm, accessed February 22th). Therefore these soils used in this study were in the range of the value reported by the Ministry of Agriculture, Forestry and Fisheries and representative of the soil in Fukushima prefecture.

\subsection{Activity Measurement}

All five earthworms were removed from soil A at 1, 2, 6, and 36 days after culturing; all five worms were removed from soil B at 1, 2, 4, 7, 14, and 22 days after culturing. 20 earthworms were cultured in the soil containing radioactive caesium for 1 week and were then transferred to radio-caesium-free soil to evaluate the clearance of radio-caesium from the worm's body. After removal from culturing, the earthworms were weighed and washed to remove soil from the body surface, placed into a vessel (cell culture dish, BD Falcon), and stored in a freezer at $-20{ }^{\circ} \mathrm{C}$. The radioactivity of each worm was measured using a p-type high-purity germanium detector (Model IGC3019, Princeton Gamma Tech) with a multi-channel analyzer (Model 7600, SEIKO EG\&G). The counting efficiency of the detector was determined by constructing a relative efficiency curve using a certified mixed radionuclide gamma-ray reference source (5054QB, Japan Radioisotope Ass.) containing ${ }^{57} \mathrm{Co}(122.1 \mathrm{keV}),{ }^{137} \mathrm{Cs}$ (661.7 keV), and ${ }^{60} \mathrm{Co}$ (1173 and $\left.1332 \mathrm{keV}\right)$. A few dead worms were used to check the counting efficiency with their body position. We found that in any position the counting efficiency was almost the same value. For every measurement, we used one efficiency curve, which was normalized to the 
$1460 \mathrm{keV}$ gamma ray peak from a ${ }^{40} \mathrm{~K}$ in $\mathrm{KCl}$ placed in the same type of vessel.”

Cs concentration ratios were calculated using the equation (1).

Concentration ratio $=\frac{\text { Average concentration of }{ }^{137} \mathrm{Cs} \text { in earthworm(Bq/wet-g) }}{\text { Concentration of }{ }^{137} \mathrm{Cs} \text { in the soil used for culturing(Bq/dry-g) }}$

The average concentration was calculated from the data for each set of five worms.

\subsection{Autoradiography}

In addition to the radioactivity measurement, 15 worms were collected, washed, and fixed with 5\% formaldehyde. After fixing, they were embedded in gel (Tissue-Tek O.C.T compound, Sakura Finetek USA), frozen at $-20{ }^{\circ} \mathrm{C}$, and cut at the mid cross-section with a cryostat (model CM 1850, Leica Biosystems). Worms were placed in contact with an imaging plate (hereafter IP, BAS-IP-MS2025E, GE Health Care, Co. Ltd.) for 3-5 days. An autoradiograph (hereafter ARG) was made by reading the IP with a Typhoon FLA 7000 reader (GE Healthcare, Co. Ltd.).

\section{Results and Discussion}

\subsection{Change of concentration ratios with time}

Changes in concentration ratios of ${ }^{137} \mathrm{Cs}$ in earthworms/dry soil are shown in Fig. 2. The concentration ratios ranged from 0.02 to 0.06 in soil A and from 0.02 to 0.22 in soil $\mathrm{B}$, and were higher at early periods of culturing, decreased gradually, and became relatively constant in both soils A and B. The higher concentrations observed at early stages of culturing may indicate active ingestion and uptake of ${ }^{137}$ Cs by E. fetida. As described below, ARG showed a distinguished accumulation of radioactivity in the digestive tract. This may indicate that the earthworms were under light starvation conditions and began consuming food (organic matter) immediately after transferal to the soil containing radio-caesium. There were significant differences in early uptake of radio-caesium by earthworms between soils A and B. The reasons for these differences are not clearly apparent, but may be attributable to the physiological conditions of worms and to soil characteristics (e.g., organic matter content, particle size). The concentration ratios appeared to be constant at approximately 0.02-0.06 after a period of culturing in both soil A and B. Transfer factors observed by Fritsch et al. (2008) were 
0.03-0.13 and the concentration ratio by ICRP Pub114(2009) was 0.048, comparable with those in our experiments. However, it is necessary to note that the transfer factors observed here are not strictly indicative of the concept of transfer.

In the soil A experiment, it was difficult to make an equation because there was not enough data. However, from the soil A experiment, it was grasped that the concentration ratios might converge to about 0.02 and that the CR had a plateau. In the soil B experiment, the plateau has not been recognized, but if the concentration ratios converged from 0.00 to 0.02 , the equations (2) could be expressed during the period when the release is dominant (after $t=4$ ) (shown at Fig. 3).

$$
\mathrm{CR}=\mathrm{CR}_{\max } \times \mathrm{e}^{-\ln 2 / \mathrm{T} \cdot \mathrm{t}}+\mathrm{a}
$$

"a" is the concentration ratio in the end of the experiment. If the equation above is assumed, the ecological half-lives are 3.0-4.6 days in the soil B experiment.

\subsection{Distribution}

The ARG and photograph of the soil and earthworms at 1, 2, 14, and 22 days after culturing in the soil B are shown in Fig. 4. The concentration of radio-caesium within the digestive tract was as high as that in the soil. In the early period, the amount of radio-caesium in the digestive tract was larger, which may indicate active food uptake by the worms. These distributions of radio-caesium were similar in the worms cultured in soil A; the concentration of radio-caesium in the body tissue was lower than that in the soil and the contents of the digestive tract. The actual ratios of radio-caesium in the body tissues of the earthworms to those in the soil may have been much lower than the nominal values shown in Fig. 2. It is noteworthy that the distribution of radio-caesium was relatively uniform throughout the earthworm’s body without any distinguishable accumulation in specific organs or tissues.

\subsection{Uptake and clearance}

The ARG (Fig. 3) showed that concentrations of radio-caesium in the body tissue of the earthworm were similar from the early to the late period of the experiment. Therefore, we examined the concentrations of ${ }^{137} \mathrm{Cs}$ in earthworms cultured up to 7 days and then moved them to radio-caesium -free soil (the soil used for routine culture of the earthworms). As shown in Table 1, concentrations of ${ }^{137} \mathrm{Cs}$ at the 1st and 2nd day after culturing in radio-caesium -free soil were very low (undetectable). The ARG and measured concentrations indicated that almost all of the radio-caesium ingested by $E$. fetida was excreted after 1 day. Since not only the contents of radio-caesium in gut but those in the worm's body were cleared, it seems that the metabolism of caesium in the earthworm is very rapid 
compared to that in mammals (e.g., 6.1 days in mice, Sato et al., 1997).

\subsection{Absorbed dose rate by internal and external exposure}

Dose conversion factors (DCFs) for 12 reference non-human organisms are provided in ICRP Pub 108 (2009). DCFs for earthworms and their eggs are shown in Table 2. The DCFs for earthworms were calculated using the following assumptions: body mass of $5.24 \times 10^{-3} \mathrm{~kg}$; body shape proportions of $10 \times 1 \times 1 \mathrm{~cm}$; and external exposure occurring from a 50-cm-thick volume source in soil. Assumptions for earthworm eggs were: mass $=6.54 \times 10^{-5} \mathrm{~kg}$; the shape proportions represented by a $0.5 \mathrm{~cm}$ diameter sphere; and the external exposure occurring from a $50-\mathrm{cm}$-thick volume source in soil. The total absorbed dose rates for ${ }^{137} \mathrm{Cs}$ were calculated for earthworms and their eggs using the highest concentrations of ${ }^{137} \mathrm{Cs}$ observed in earthworms in soils $\mathrm{A}$ and $\mathrm{B}$ for internal exposure and the observed concentrations of ${ }^{137} \mathrm{Cs}$ in soils A and B for external exposure, respectively (Table 3). The shape and size of the earthworms used in this experiment were in the range between those of worms and eggs used by the ICRP Pub108 (2009) to obtain DCFs; the total absorbed dose rates were calculated using these factors for soils A and B (Table 3). The external doses are up to 10 times greater than internal doses. Therefore, the most important pathway was external exposure. The concentration of ${ }^{134} \mathrm{Cs}$ was measured in selected samples with high radioactivity. The ratio of the radioactive concentration of ${ }^{134} \mathrm{Cs}$ to ${ }^{137} \mathrm{Cs}$ was $0.5 \sim 0.8$. Assuming ${ }^{134} \mathrm{Cs}$ was distributed at the same concentrations as ${ }^{137} \mathrm{Cs}$ for conservative dose estimation, the total absorbed dose rates from both radio-caesium may be approximately $4.2 \times 10^{2}$ and $1.9 \times 10^{3} \mu \mathrm{Gy} /$ day in soils A and B, respectively.

The DCFs provided by the ICRP Pub108 (2009) are based on two additional assumptions: uniform distribution of radionuclide in the earthworm body, and uniform, $50 \mathrm{~cm}$ depth distribution of radionuclides in the soil. However, as noted, the concentrations of radio-caesium in the GI-tract were much higher than those in the earthworm body tissues. In other words, the concentrations of radio-caesium in real tissue were much lower than the measured values indeed. Since the concentrations of radio-caesium seemed be the same as those of the soil, the exposure of the GI-tract was similar to the external exposure. If the internal exposure was to exclude the inside of the GI-tract and if the GI-tract exposure was to be considered as the external exposure, the internal dose rate determined using ICRP DCFs may give higher (conservative) values. The external dose rates may also be overestimated because the contaminated soil layer was approximately $15 \mathrm{~cm}$ deep in this experiment, and less than $10 \mathrm{~cm}$ in the actual environmental situations reported by IAEA (2006) and Bondarkov et al., (2011).

ICRP described in the publication 108 that the derived consideration reference level of reference earthworm was 10-100mGy per day. IAEA (1992) and UNSCEAR (1996) said that 1mGy/day does not appear likely to cause observable changes in terrestrial animal population, and $10 \mu \mathrm{Gy} / \mathrm{h}$ (0.24mGy/day) is the ERICA screening dose rate value (J.E.Brown et al, 2008). The ERICA screening 
dose rate value is considerably conservative (Kawaguchi et al, 2008). Therefore, the highest absorbed dose rate, overestimated in the present study and higher than 1mGy/day, would have no biological consequences in the actual earthworms.

\section{Conclusion}

The concentration ratios with time were obtained for 2 concentration soils in this study. These concentration ratios were comparable to the values in other studies. The ecological half-life of the earthworm was estimated to be 3.0 - 4.6 days. In real tissue, the distribution of radio-caesium was relatively uniform throughout the earthworm's body without any distinguishable accumulation in specific organs or tissues. The autoradiography and the depuration results seem to suggest that a large amount of the activity in the organisms is due to residual soil in the gut, and thus it is not strictly true to say that the radio-caesium had been actively taken up by the organisms. Also it was found that the most important pathway for the earthworms was external exposure and the highest absorbed dose rate, overestimated in the present study, would have no biological consequences in actual earthworms.

\section{Acknowledgements}

The authors sincerely appreciate the useful advice of Dr. S. Yoshida and Dr. Nakamori of the National Institute of Radiological Sciences. A part of this study was supported by the KUR Research Program for Scientific Basis of Nuclear Safety.

\section{References}

Bondarkov, M. D. B., Oskolkov, Ya., Gaschak, S. P., Kireev, S. I., Maksimenko, A. M., Proskura, N. I., Jannki, G. T., and Farfan, E. B., 2011. Environmental Radiation Monitoring in the Chernobyl Exclusion Zone - History and Results 25 Years After, Health Phys. 101: 442 - 485.

Brown, J.E., Alfonso, B., Avila, R., Beresford, N.A., Copplestone, D., Pröhl, G., Ulanovsky A., 2008. The ERICA Tool, J. Environ. Radioact., 99, 1371-1383.

Fritsch, C., Scheifler, R., Beaugelin-Seiller, K, Hubert, P., Cœurdassier, M., de Vaufleury, A. and Badot, P-M., 2008. Biotic interactions modify the transfer of cesium-137 in a soil-earthworm-plant-snail food web. Environ. Toxicol. Chem. 27: 1698-1707.

Fritzpatrick, L.C., Muratti-Oritz, J.F., Venables, B.J. and Goven, A.J., 1996. Comparative toxicity in earthworms Eisenia fetida and Lumbricus terrestris exposed to cadmium nitrate using artificial soil and filter paper protocols. Bull. Environ. Contam. Toxicol. 57: 63-68. 
Greig-Smith, P.W., Becker, H., Edwards, P.J., and Heimback, F., Eds., 1992. Ecotoxicology of Earthworms, Intercept Ltd., Andover, U.K., pp 269.

IAEA, 1992. Effects of ionising radiation on plants and animals at levels implied by current radiation protection standards. Technical Reports Series No. 332.

IAEA, 2006. Environmental Consequences of the Chernobyl Accident and their Remediation: Twenty Years of Experience. Report of the Chernobyl Forum Expert Group 'Environment'

ICRP, 2003. A Framework for Assessing the Impact of Ionising Radiation on Nom-human Species. Annals of the ICRP Publication 91, Pergamon Press, Oxford.

ICRP, 2007. The 2007 Recommendations of the International Commission on Radiological Protection. Annals of the ICRP Publication 103, ELSEVIER.

ICRP, 2009. Environmental Protection: the Concept and Use of Reference Animals and Plants. Annals of the ICRP Publication 108, ELSEVIER.

ICRP, 2009. Environmental Protection: Transfer Parameters for Reference Animals and Plants. Annals of the ICRP Publication 114, ELSEVIER.

Janssen, M.P.M., Glastra, P. and Lembrechts, J.F.M.M., 1996. Uptake of ${ }^{134}$ Cs from a sandy soil by two earthworm species: The effects of temperature. Arch. Environ. Contam. Toxicol. 31: 184-191.

Kawaguchi I., Takahashi T., Uchida S., Investigation on Applicability of Biota Dose Assessment Model to Japanese Environment., 2008, Jpn. J. Health Phys., 43(3), 282-289.

Lavelle, P., Bignell, D., Lepage, M., Wolters, V., Roger, P., Ineson, P., Heal, O.W. and Dhillion, S., 1997. Soil function in a changing world: The role of invertebrate ecosystem engineers. Eur. J. Soil Biol. 33: 159-193.

Sato I., Matsusaka N., Tsuda S., Kobayashi H., and Nishimura Y., 1997. Relationship between Turnover of Cesium-137 and Dietary Potassium Content in Potassium-Restricted Mice. Radiat. Res. 148: 98-100.

Suzuki K., Suzuki T., Stürzenbaum S., Gamou S., 2008. Construction of a Bacterial Artificial Chromosome (BAC) Library and the Genomic Analysis of Valosine-Containing Proteins in the earthworm Eisenia fetida. , Eur. J. Soil Biol. 44: 202-206.

UNSCEAR, 1996. Effects of radiation on the environment. United Nations Scientific Committee on the Effects of Atomic Radiation, Report to the General assembly, Annex 1.

UNSCEAR, 2013. United Nations Scientific Committee on the Effects of Atomic Radiation, General Assembly Official Records Sixty-eighth session Supplement No.46. 
Table 1. Depuration of earthworm

\begin{tabular}{|c|c|c|c|c|c|}
\hline \multirow{3}{*}{$\begin{array}{c}\text { Concentration } \\
\text { (Bq/wet-g) }\end{array}$} & \multicolumn{3}{|c|}{ Soil with radioactive substances } & \multicolumn{2}{|c|}{ Soil without radioactive substances } \\
\hline & 1st day & 2nd day & 7th day & 1st day & 2nd day \\
\hline & $6.3 \pm 1.3^{*}$ & $4.7 \pm 1.6^{*}$ & $7.0 \pm 2.2^{*}$ & ND** & ND** \\
\hline
\end{tabular}

The concentrations of ${ }^{137} \mathrm{Cs}$ in earthworms on the 1st, 2nd, and 7th day after culturing in soil containing radioactive isotopes were similar. ${ }^{137} \mathrm{Cs}$ is not detected in earthworms on the 1st and 2nd day after culturing in soil without radioactive isotopes.

*Values are average concentrations of ${ }^{137} \mathrm{Cs}$ in earthworms \pm standard deviation. $(\mathrm{N}=5)$

**ND: not detectable. 
Table 2. Dose conversion factors (DCFs) for Earthworm, its eggs and mean DCFs ( $\mu \mathrm{Gy} / \mathrm{day}) /(\mathrm{Bq} / \mathrm{kg})$

\begin{tabular}{|c|c|c|c|c|c|c|}
\hline DCFs & \multicolumn{2}{|c|}{ Earthworm } & \multicolumn{2}{|c|}{ Earthworm egg } & \multicolumn{2}{|c|}{ Mean } \\
\hline \multirow{2}{*}{${ }^{137} \mathrm{Cs}$} & Internal & External & Internal & External & Internal & External \\
\hline & $3.4 \times 10^{-3}$ & $7.3 \times 10^{-3}$ & $2.8 \times 10^{-3}$ & $8.4 \times 10^{-3}$ & $3.1 \times 10^{-3}$ & $7.9 \times 10^{-3}$ \\
\hline \multirow{2}{*}{${ }^{134} \mathrm{Cs}$} & Internal & External & Internal & External & Internal & External \\
\hline & $2.6 \times 10^{-3}$ & $2.0 \times 10^{-2}$ & $2.0 \times 10^{-3}$ & $2.2 \times 10^{-2}$ & $2.3 \times 10^{-3}$ & $2.1 \times 10^{-2}$ \\
\hline
\end{tabular}

Assumptions for DCFs for earthworms: body mass $=5.24 \times 10^{-3} \mathrm{~kg}$; body shape proportions are $10 \times 1$ $\times 1 \mathrm{~cm}$; external exposure occurs in a 50 -cm-thick volume source in soil.

Assumptions for DCFs for earthworm eggs: mass $=6.54 \times 10^{-5} \mathrm{~kg}$; shape proportions are represented by a $0.5-\mathrm{cm}$ diameter sphere; external exposure occurs in a 50 -cm-thick volume source in soil.

Mean DCFs are the average DCFs for earthworms and eggs. 
Table 3. Absorbed dose rate from internal and external exposure of earthworm to ${ }^{137} \mathrm{Cs}$

\begin{tabular}{|c|c|c|c|c|c|c|c|c|c|c|c|}
\hline DCFs & Experiment & \multicolumn{4}{|c|}{ Concentration of ${ }^{137} \mathrm{Cs} * *$} & \multicolumn{6}{|c|}{ Absorbed dose rate from ${ }^{137} \mathrm{Cs}^{* *}$} \\
\hline \multirow{2}{*}{ Earthworm } & soil A & 3.1 & \pm 1.6 & 14 & \pm 0.73 & 11 & \pm 5.4 & 100 & \pm 5.3 & 110 & \pm 11 \\
\hline & soil B & 35 & \pm 4.0 & 60 & \pm 0.24 & 120 & \pm 14 & 440 & \pm 1.8 & 560 & \pm 15 \\
\hline Mean* & soil B & 35 & \pm 4.0 & 60 & \pm 0.24 & 110 & \pm 12 & 470 & \pm 1.9 & 580 & \pm 14 \\
\hline Earthworm & soil A & 3.1 & \pm 1.6 & 14 & \pm 0.73 & 8.7 & \pm 4.5 & 120 & \pm 6.1 & 130 & \pm 11 \\
\hline egg & soil B & 35 & \pm 4.0 & 60 & \pm 0.24 & 99 & \pm 11 & 510 & \pm 2.0 & 600 & \pm 13 \\
\hline
\end{tabular}

The highest observed concentration of ${ }^{137} \mathrm{Cs}$ was used to calculate the internal exposure of earthworms.

The observed concentration of ${ }^{137} \mathrm{Cs}$ in soil was used to calculate external exposure.

*Mean DCFs are average values for earthworms and eggs.

$* *$ Value \pm error. 


\section{Figure captions}

Fig. 1 . Map of Fukushima Prefecture

The locations where the soils were collected are shown.

Fig. 2 . Change of concentration ratios with time.

The concentration ratios of ${ }^{137} \mathrm{Cs}$ in earthworms/soil were high early in the culturing period and decreased gradually. $\mathrm{N}=5$; bars indicate one standard deviation.

Fig. 3. The plot of form fitted to soil B experiment If $\mathrm{CR}$ had a plateau in the soil $\mathrm{B}$ experiment, the equation could be expressed with " $\mathrm{CR}=\mathrm{CR}_{\max } \times \mathrm{e}^{-\ln 2 / \mathrm{T} \cdot \mathrm{t}}+\mathrm{a}$ " during the period when release is dominant(after $t=4$ ) where "a" is the concentration ratio in the end of the experiment.

Fig. 4 . Autoradiograph and photograph of soil and earthworms at the 1st, 2nd, 14th, and 22nd day after culturing. Red color indicates high radio-cesium concentration; green indicates areas of lower concentration. Blue represents background concentrations. 


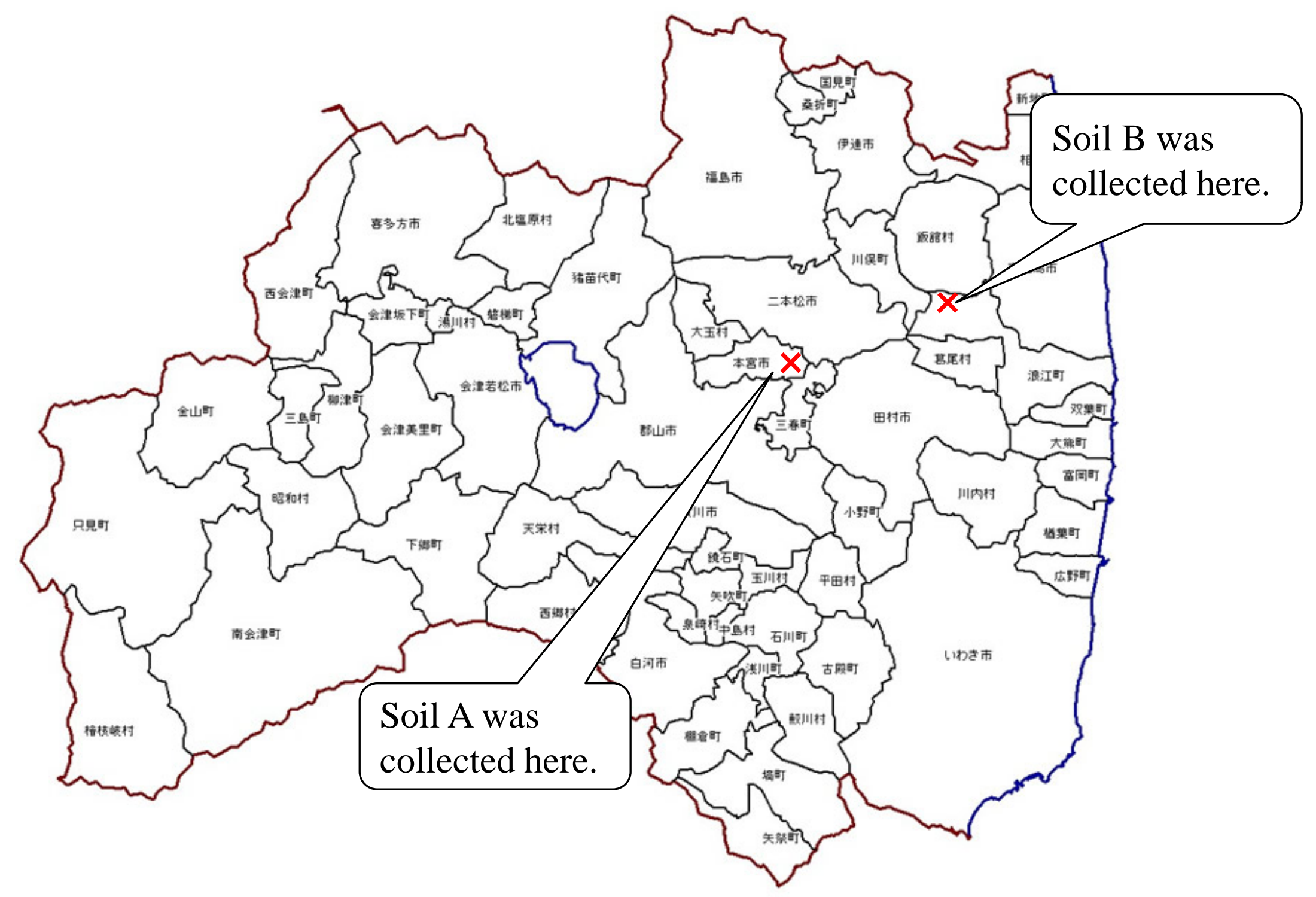

Fig.1 


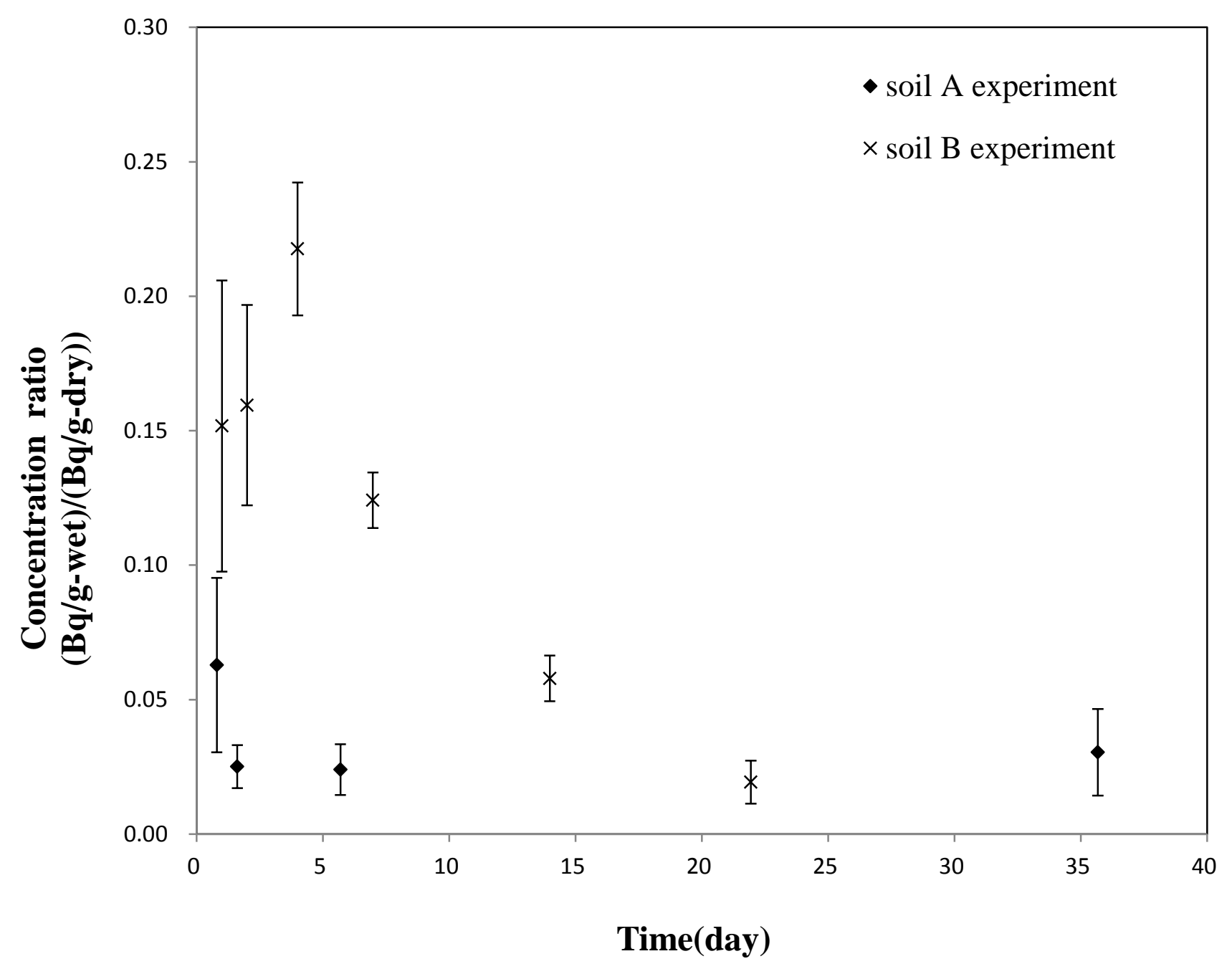

Fig.2 


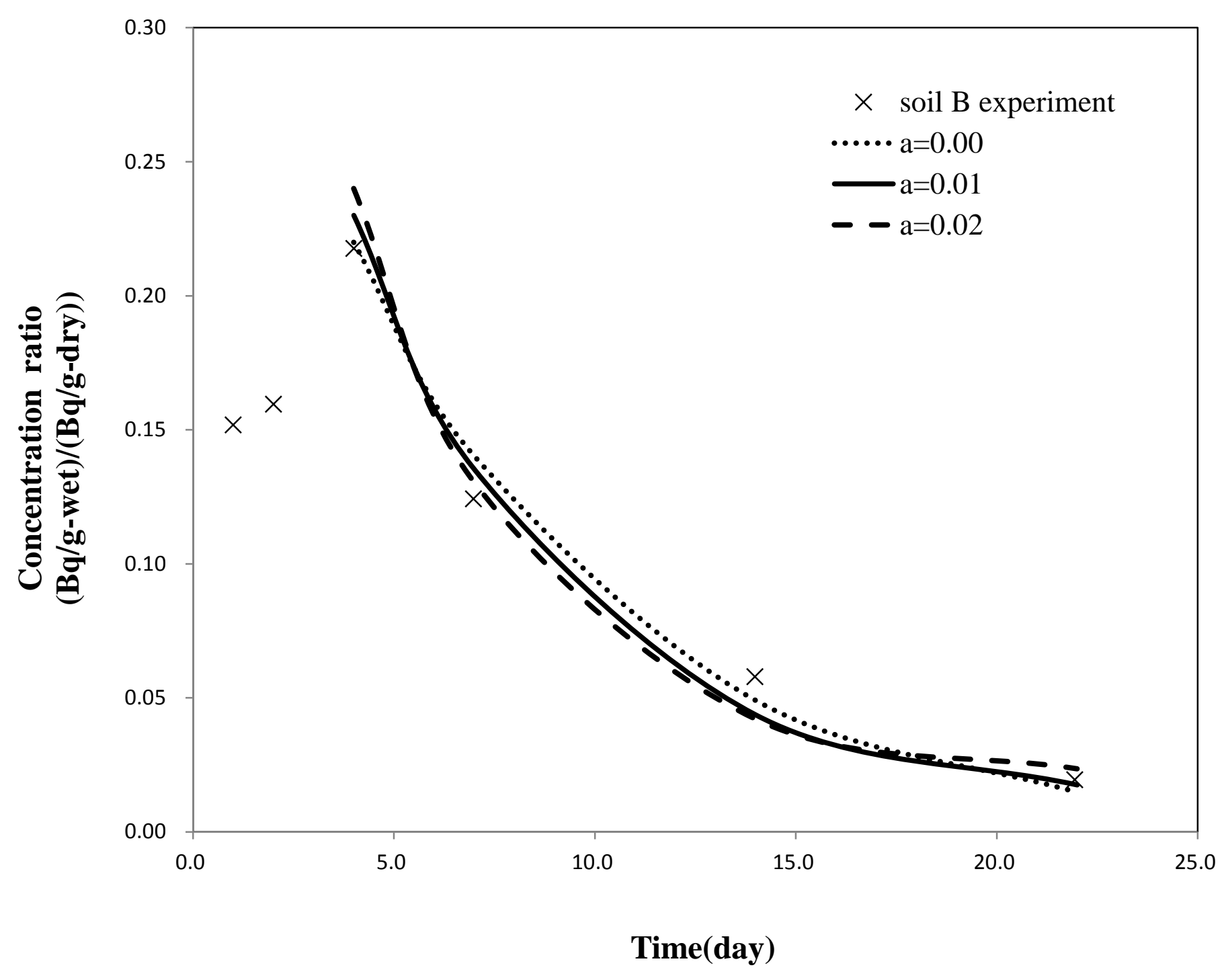

Fig.3 

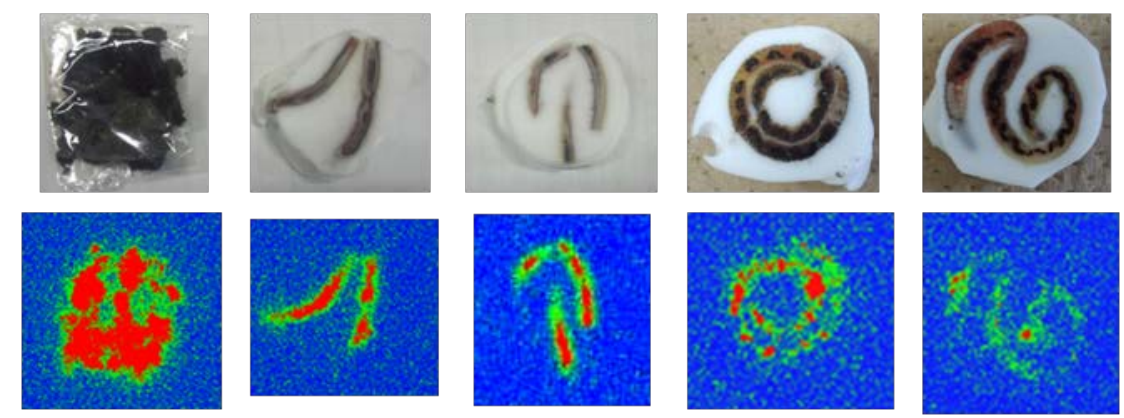

Soil

The 1st day

The 2nd day

The 14th day

The 22th day

\section{Fig.4}

